\title{
Bone marrow-derived mesenchymal stromal cells promote colorectal cancer cell death under low-dose irradiation
}

\author{
Hao Feng ${ }^{1,2}$, Jing-kun Zhao ${ }^{1,2}$, Tobias S Schiergens ${ }^{2}$, Pu-xiongzhi Wang ${ }^{1}$, Bao-chi Ou ${ }^{1}$, Rami Al-Sayegh ${ }^{2}$, \\ Ming-lun $\mathrm{Li}^{3}$, Ai-guo Lu ${ }^{\star}, 1$, Shuai Yin ${ }^{\star, 1,2,4}$ and Wolfgang $\mathrm{E}$ Thasler ${ }^{5}$ \\ ${ }^{1}$ Department of General Surgery, Ruijin Hospital, Shanghai Jiao Tong University School of Medicine, Shanghai 200025, China; \\ ${ }^{2}$ Department of General-, Visceral-, Transplantation and Vascular Surgery, University Hospital of LMU Munich, Munich 81377, \\ Germany; ${ }^{3}$ Department of Radiation Oncology, University Hospital of LMU Munich, Munich 81377, Germany; ${ }^{4}$ Department of \\ General Surgery, State Hospital of Anhui Province, Hefei 230000, China and ${ }^{5}$ Department of General and Visceral Surgery, Red \\ Cross Hospital, Munich 80634, Germany
}

Background: Radiotherapy remains one of the cornerstones to improve the outcome of colorectal cancer (CRC) patients. Radiotherapy of the CRC not only help to destroy cancer cells but also remodel the tumour microenvironment by enhancing tumour-specific tropism of bone marrow-derived mesenchymal stromal cell (BM-MSC) from the peripheral circulation. However, the role of local MSCs and recruited BM-MSC under radiation were not well defined. Indeed, the functions of BM-MSC without irradiation intervention remained controversial in tumour progression: BM-MSC was previously shown to modulate the immune function of major immune cells, resulting in an impaired immunological sensitivity and to induce an increased risk of tumour recurrence. In contrast, it could also secrete various cytokines and possess anticancer effect.

Methods: Three co-cultivation modules, 3D culture modules, and cancer organoids were established. The induction of cytokines secretion in hBM-MSCs after irradiation was analysed by ELISA array and flow cytometry. AutoMac separator was used to separate hBM-MSC and CRC automatically. Cells from the co-cultured group and the control group were then irradiated by UV-C lamp and $\mathrm{X}$-ray. Proliferation assay and viability assay were performed.

Results: In this study, we show that BM-MSCs can induce the EMT progression of CRC cells in vitro. When irradiated with low doses of ultraviolet radiation and X-rays, BM-MSCs show an anti-tumour effect by secreting certain cytokine (TNF- $\alpha$, IFN- $\gamma$ ) that lead to the inhibition of proliferation and induction of apoptosis of CRC cells. This was further verified in a 3D culture model of a CRC cell in vitro. Furthermore, irradiation on the co-culture system induced the cleavage of caspase 3 , and attenuated the phosphorylation of phosphatidylinositol 3-kinase (PI3K)/AKT and extracellular signal-regulated kinase in cancer cells. The signal pathways above might contribute to the cancer cell death.

Conclusions: Taken together, we show that BM-MSC can potentially promote the effect of radiotherapy in CRC.

*Correspondence: Dr S Yin; E-mail: daladaladi@gmail.com or Professor A-g Lu; E-mail: aiguoadams.lu@yahoo.com

Received 17 April 2017; revised 3 October 2017; accepted 23 October 2017; published online 2 January 2018

(C) 2018 Cancer Research UK. All rights reserved 0007-0920/18 
Colorectal cancer (CRC) remains one of the most common cancers worldwide, with $\sim 746000$ and 614000 new diagnosed cases per year in men and women, respectively (Schreuders et al, 2015). Despite rapid advances in multiple therapy strategies of cancer, the efficacy of current treatment strategies is still far from expected.

Mesenchymal stromal cells (MSCs) are a heterogeneous group of progenitor cells that are important for tissue regeneration. Cancer is considered as 'wounds that never heal' and thus MSCs, in response to chemokine, are continuously recruited and integrated into the tumour microenvironment. MSCs within tumour microenvironment could exert both pro-apoptotic and pro-survival effects on tumours and modulate the immune functions by altering the cytokine secretion profile of antigen presenting cells, $\mathrm{T}$ cells, and natural killer cells. It has been proven that MSCs could secrete various cytokines and possess anticancer effects (Pommey and Galipeau, 2006; Hendijani and Javanmard, 2015; Liotta et al, 2015). However, on the other hand, evidence was provided that MSC could also induce an inflammatory and immune suppression microenvironment, resulting in an impaired immunological sensitivity and the promotion of tumour growth, which gives rise to an increased risk of tumour recurrence (Houthuijzen et al, 2012; Chen et al, 2015).

In radiation oncology, classical viewpoints insist ionising radiation works by penetrating and damaging the DNA of cancerous tissue, which leads to cellular death. However, the complex interaction between the cancer cell and stromal cells, especially the function of MSCs under radiation, are not very much investigated. Owing to the complexity of interactions of different cell types within the tumour microenvironment, we speculated that the components of tumour microenvironment could also affect the systemic anti-cancer effect of radiotherapy. At present, researchers used heterogeneous culture of marrow stromal cells and claim they are MSCs. Actually, MSCs contain several sub-populations: stromal cells, progenitor cells, fibroblasts, and stem cells. In the present study, the authors used MSCs containing a subpopulation of stem cells (Galderisi and Giordano, 2014). Considering multipotency and tumour tropism of MSCs, we further supposed that MSCs could either sensitive or blunt the radiotherapy effect in CRC. Growing evidence has shown that low doses of radiation also have profound effects on cellular functions. Concerning stem cells, owing to their longer lifespan, they could sustain more rounds of lower doses of radiation, which may severely affect cellular function but not cellular physiology (Fazel et al, 2009). In addition, low doses of radiation could have already induced a reduction in cycling MSCs and an increase in apoptotic cells, and these proportions did not grow progressively as the doses increased (Alessio et al, 2015).

To verify this hypothesis, we investigated the radiotherapy sensitivity of CRC cell and bone marrow-derived mesenchymal stromal cell (BM-MSC) under radiation in vitro. Our finding suggests that: (1) MSCs can induce the mesenchymal phenotype of CRC in vitro; (2) BM-MSCs under low-dose radiation show an anti-tumour effect in 2D and 3D co-cultivation models by secreting certain cytokine (TNF- $\alpha$, IFN- $\gamma$ ). (3) Irradiation on the co-culture system induced the cleavage of caspase 3 , and attenuated the phosphorylation of phosphatidylinositol 3-kinase (PI3K)/AKT and extracellular signal-regulated kinase (ERK) in cancer cells. PI3KAkt signalling pathway is a signal transduction pathway that promotes survival and growth in response to extracellular signals. The suppression of this signalling pathway might lead to cancer cell death. Therefore, the combination of administration of MSC with radiotherapy might improve the outcome of CRC patients. This study provides clues for an improved therapy alternative to sensitise radiotherapy in CRC patients.

\section{MATERIALS AND METHODS}

Cell lines. Human CRC cell lines (HT-29, SW1116, and SW620) were obtained from Shanghai Digestive Surgery Key Lab, which was purchased and generated from American Type Culture Collection (Manassas, VA, USA). CRC cells were cultured in RPMI 1640 medium with GlutaMAX (GIBCO) supplemented with $10 \%$ fetal bovine serum (FBS) and penicillin-streptomycin (100 $\mathrm{U} \mathrm{ml}^{-1}$ penicillin, $100 \mathrm{\mu g} \mathrm{ml}^{-1}$ streptomycin). Cells were maintained at $37^{\circ} \mathrm{C}$ in a $5 \% \mathrm{CO}_{2}$ incubator (Thermo Fisher Scientific, Darmstadt, Germany) according to standard protocols. Pancreatic cancer BxPC3 and DanG cell lines were cultured in GIBCO Dulbecco's Modified Eagle Medium (DMEM, Thermo Fisher Scientific). The medium was replaced routinely every 2-3 days. When $70-80 \%$ cell confluence has reached, the cells were sub-cultured. Poietics Normal Human Bone Marrow-Derived Mesenchymal stromal cells were complimentary from Group of Dr med Tobias Schiergens, which were purchased from Lonza (Walkersville, MD, USA) (Mayer-Wagner et al, 2011). MSC was cultured in StemMACS MSC Expansion Media (130-091-680, Miltenyi Biotec, Bergisch Gladbach, Germany) supplemented with human StemMACS MSC Expansion Media Kit XF (Miltenyi Biotec), 10\% FBS (VWR Life Science, Visalia, CA, USA) and penicillin-streptomycin. Fibroblast was isolated from cancer specimens of CRC patients. The project was approved by the Research Ethics Boards of Ruijin Hospital affiliated to Shanghai Jiao Tong University and the informed consent was signed by the patients.

Cell counting. The growth medium was discarded from the culture dish (Corning, Inc., Christiansburg, VA, USA) and the remaining adherent cells were collected by trypsinisation. Cells were then counted with the CASY TT Cell Counter (Roche Diagnostics, Indianapolis, IN, USA). Viable cells were discriminated from dead/apoptotic cells by trypan blue exclusion.

UV and ionising irradiation. Cells were seeded at a density of $2.5 \times 10^{3}$ cells $\mathrm{cm}^{-2}$ in 12 -well plates. On the next day, Cells were irradiated with a $254 \mathrm{~nm}$ UV-C lamp (UVP Inc., Upland, CA, USA) at a dose of $10 \mathrm{~J} \mathrm{~m}^{-2}$, which was measured with a UVX radiometer. Irradiated cells were allowed to grow for $48 \sim 72 \mathrm{~h}$ without changing the medium, according to a previously published protocol, the dose has also been indicated in this publication ( $\mathrm{Lu}$ et al, 2012). Supernatant and the adherent cells growing on the dish were collected, respectively. Viable adherent cells were counted. For X-rays irradiation, cells were irradiated with an RS225 X-Ray irradiator $(200 \mathrm{kV}, 10 \mathrm{~mA}, 1 \mathrm{~Gy}$ per $66 \mathrm{~s})$ with the total dose of $10 \mathrm{~Gy}$. After irradiation, cells were returned to the incubator and incubated for $24-48 \mathrm{~h}$. The dose of the ultraviolet radiation and ionising radiation used in this manuscript has been indicated in other publications (Brozyna et al, 2007; Gullo et al, 2008; Deacon et al, 2008; Sato et al, 2014; Fujita et al, 2015). The optimal condition has also been confirmed by our preliminary experiment.

The co-culture model. To investigate the interaction of CRC cells with MSCs, we used three different co-culture models: the wedgegap dish (Figure 1D), $\mu$-Slide $2 \times 9$ well (ibidi, Munich, Germany, Figure $2 \mathrm{~F}$ ), and ibidi culture insert $\mu$-dish (ibidi, Supplementary Figure 1C). For $2 \times 9$ well $\mu$-Slide, $50 \mu$ l CRC cells were seeded in the centre minor well and $50 \mu \mathrm{l}$ MSCs in each surrounding well at a density of $2.5 \times 10^{3}$ cells cm ${ }^{-2}$. After cell attachment, $500 \mu \mathrm{l}$ RPMI1640 complete growth medium was added to the whole growth area, allowing the cells in different nine wells to share common growth medium under irradiation. For wedge-gap dishes (Figure 1D), $2 \mathrm{ml}$ suspended CRC cells and $4 \mathrm{ml}$ suspended MSCs were seeded in the inner dish and outer dish, respectively (MSC was seeded $12 \mathrm{~h}$ later after the attachment of CRC cells), with the 
A
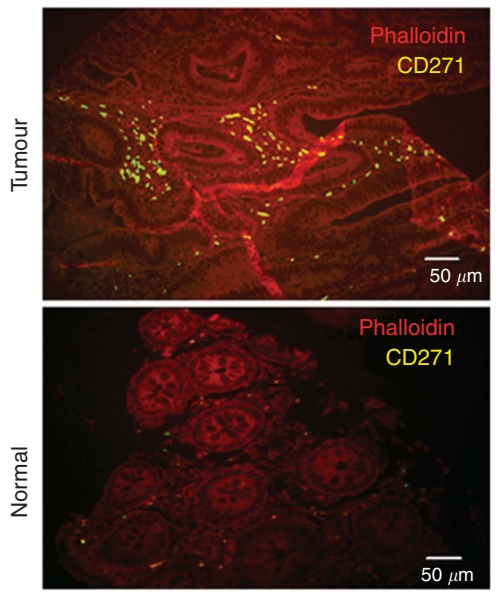

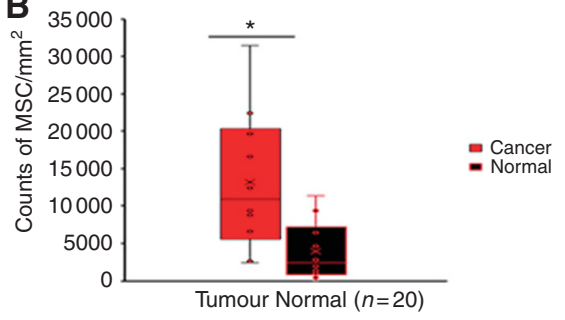

C

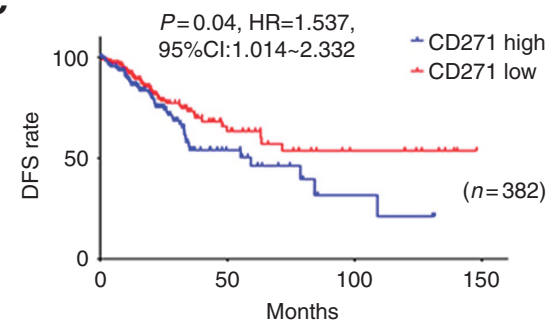

D

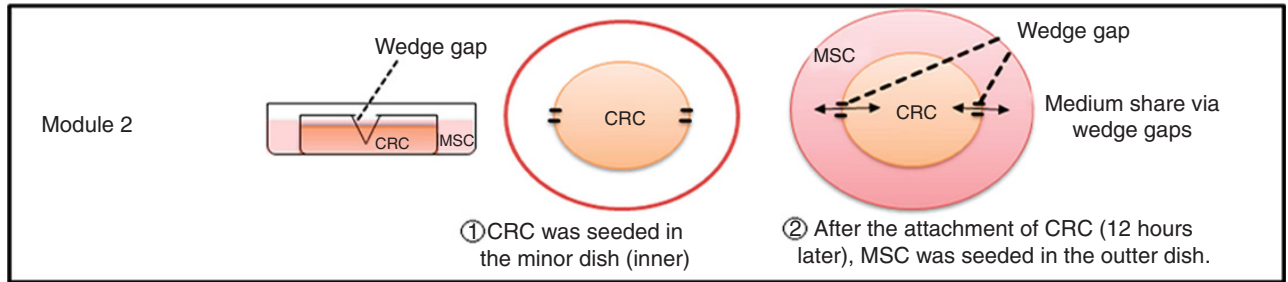

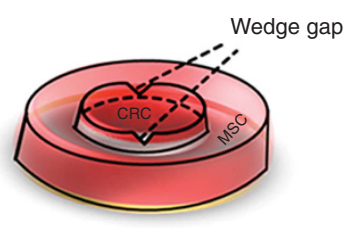

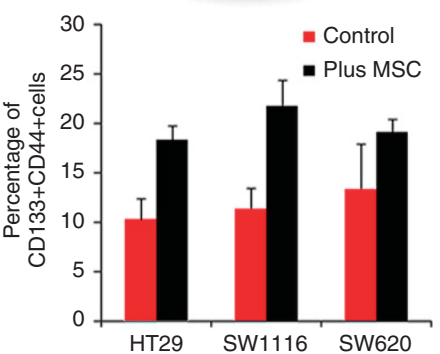

E

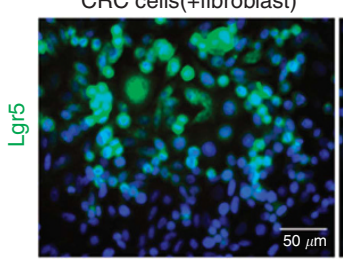

CRC cells(+MSC)

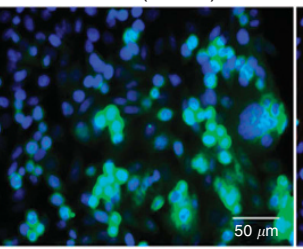

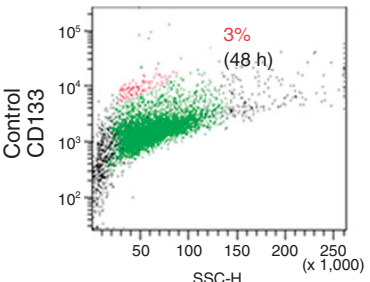
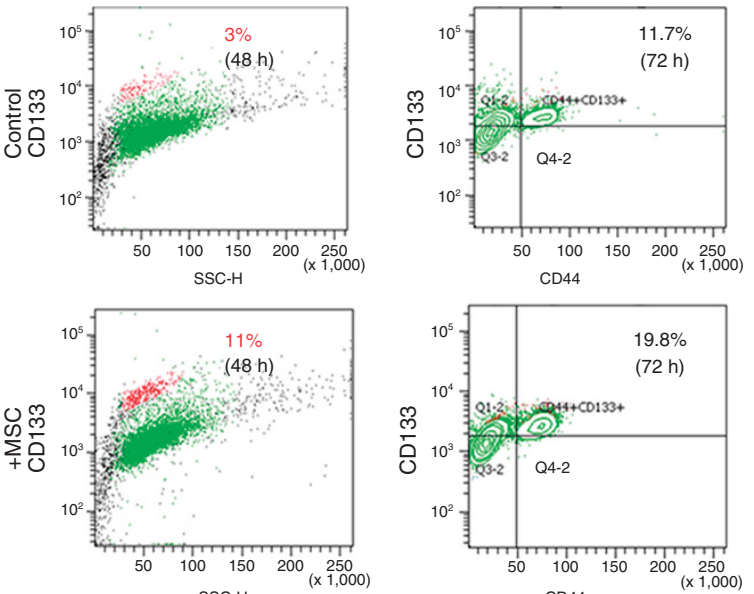

SSC-H

CRC cells (control)

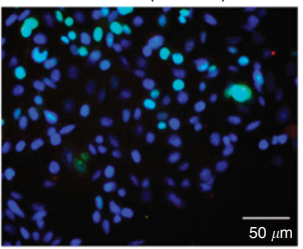

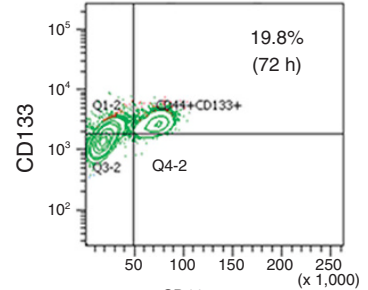

CD44

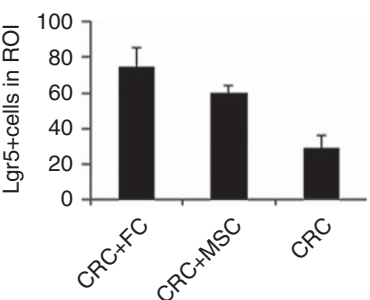

Figure 1. Co-cultivation with MSCs promoted colorectal cancer cells (CRC) to obtain stemness in vitro. (A) Human colorectal cancer tissues and adjacent normal tissues were stained with the anti-CD271 antibody (MSCs marker, yellow). MSCs could be found surrounding the tumour lesions (200x). (B) Counts of CD271 + MSCs of the slides were calculated respectively using ImageJ. MSCs were enriched in tumour site (Red box) compared with normal tissues (black box). (C) Disease-free survival (DFS) rate was analysed basing on TCGA data set. Patients were separated into CD271 mRNA z-score high and low groups. (D) Co-cultivation model for MSCs and CRC. The $3.5 \mathrm{~cm}$ and $10 \mathrm{~cm}$ dish share medium through two wedge gaps when the medium is enough to reach the level of the wedge gap. If the medium did not reach the wedge gap level, cells in two dishes could grow independently. FACS analysis of CD133 + CRC stem cell-like cells, CD133 + CD44 + stem cell-like cells before and after co-cultivation with MSCs. Three cell lines HT29, SW1116, and SW620 were taken into consideration. (E) Immunofluorescence staining and quantification showed the proportion of LGR5 + CRC stem cell-like cells increased after co-cultured with fibroblast or mesenchymal stromal cells compared with control group. ${ }^{\star} P<0.05$. 
density of $2.5 \times 10^{3}$ cells cm ${ }^{-2}$. Similarly, $15 \mathrm{ml}$ RPMI1640 complete growth medium was added into dishes after cell attachment, allowing inner and outer cells to share growth medium. Cells were then treated with irradiation for $24-48 \mathrm{~h}$.

Wound-healing assay of MSC and CRC cell. Wound-healing assay of 'two different cell line' was performed to investigate the interactions of different cell types. For this purpose, MSCs and CRC cells $\left(2.5 \times 10^{3}\right.$ cells $\left.\mathrm{cm}^{-2}\right)$ were seeded into each well in ibidi's $\mu$-Dish ${ }^{35} \mathrm{~mm}$,high (ibidi), respectively. (Supplementary Figure 1B). The insert was removed after cell attachment and $3 \mathrm{ml}$ RPMI 1640 complete growth medium was added to the culture dish. For the control group, both wells in the insert were seeded with the same cell line (either CRC cells or MSCs). Subsequently, the co-culture system was treated with irradiation of $10 \mathrm{~J} \mathrm{~cm}^{-2}$ for $96 \mathrm{~h}$, with irradiation untreated cells as the control group.

Cell proliferation assay and colony formation assay. For cell proliferation assay (Figure $3 \mathrm{~A}$ ), $4 \times 10^{4}$ SW1116 or HT29 cells were seeded with or without (the control group) $1 \times 10^{4}$ MSCs in 12 -well plate. The cells were then treated with $10 \mathrm{~J} \mathrm{~cm}^{-2}$ irradiation for $1 \mathrm{~h}$ per $6 \mathrm{~h}$. Total cells in each well were counted at $12 \mathrm{~h}, 36 \mathrm{~h}$, and $72 \mathrm{~h}$, respectively.

Similarly, in Figure 3C and D, CRC cells and MSCs was mixed and seeded in ultra-low attachment 24 -well plates with a different ratio (CRC: MSCs, 25:25, 50:25, 100:25, 200:25). The same number of CRCs seeded without MSCs in the plate was used as the control group. Different amounts of CRC cells (50, 75, 125, and 225), which were seeded in the plate, respectively, was used as the blank control. Cells were then treated with $10 \mathrm{~J} \mathrm{~cm}^{-2}$ irradiation for $1 \mathrm{~h}$ per $8 \mathrm{~h}$, lasting for 8 days. Cell colonies were counted on the 9 th day. Independent experiments were repeated at least three times.

In Figure 3E, $6 \times 10^{6} \mathrm{CRC}$ cells were mixed with or without $10^{6}$ MSC cells and then seeded in the co-culture system (Supplementary Figure 1B). Cells were treated with $10 \mathrm{~J} \mathrm{~cm}^{-2}$ irradiation for $1 \mathrm{~h}$ per $8 \mathrm{~h}$. Total cells in each well were counted at $24 \mathrm{~h}, 48 \mathrm{~h}, 72 \mathrm{~h}, 96 \mathrm{~h}$, and $120 \mathrm{~h}$, respectively.

CFSE cell proliferation assay. CRC cells were collected and pelleted from the co-culture model 2 (Supplementary Figure B) from the experiment group and the control group, respectively. After washed with PBS twice, CRC cells were re-suspended and incubated with CellTrace CFSE (1:1000 dilution) staining solution for $20 \mathrm{~min}$ in dark. Cells were pelleted again and resuspended in fresh pre-warmed complete culture medium. The results were analysed by flow cytometry. The experiments were repeated three times.

ELISA. Culture medium from the co-culture system after irradiation was collected at 6,12 , and $24 \mathrm{~h}$, respectively. Cytokines concentration was determined by sandwich ELISA using a Human Th1/Th2/Th17 Cytokines Multi-Analyte ELISArray Kit (Qiagen, Hilden, Germany), following the manufacturer's instructions.

Immunoblot analysis. Cells were homogenised and lysed in RIPA buffer supplemented with proteinase inhibitor. An equal amount of proteins $(25 \mu \mathrm{g})$ were loaded and run on $12 \%$ SDS-PAGE gel and transferred onto PVDF membranes following electrophoresis. After the incubation with 5\% milk in TBS/T for $1 \mathrm{~h}$, the membrane was incubated with the primary antibodies at $4{ }^{\circ} \mathrm{C}$ overnight. The primary antibodies used in this experiment were: anti-total AKT, anti-total Erk, anti-Phospho-AKT, anti-Phospho Erk1/2, antiprocaspase 3, anti-Caspase3, anti-PI3K, anti-beta-actin, antiGFAP, anti-vimentin, anti-desmin, anti-alpha-smooth muscle actin, and anti-Phospho Stat3 (Cell signaling, Danvers, MA, USA). GAPDH (Cell Signaling) was used as the loading control.

Immunofluorescence. Cells cultured in eight-well chamber slides (Falcon, BD, Germany) and culture-inserts (ibidi) were washed twice with cold PBS, fixed with $4 \%$ para-formaldehyde for 15 min, permeabilised with $0.1 \%$ Triton X-100 for 5 min, blocked with $5 \%$ BSA, incubated with indicated primary antibodies: anti-GFAP and anti-desmin (Sigma, Darmstadt, Germany), antiLgr5 (Abcam, Cambridge, UK), anti- $\alpha$-SMA, and anti-Vimentin (R\&D, Minneapolis, MN, USA), APC-anti-CD271 (Miltenyi Biotech, Auburn, CA, USA) at $4{ }^{\circ} \mathrm{C}$ overnight and followed by anti-rabbit Alexa fluor 488 secondary antibody and anti-mouse Alexa Fluor 568-conjugated secondary antibody (Life technology, Darmstadt, Germany). The cells were then stained with anti-fade DAPI (Life Technology) for nuclear staining, and the images were acquired with an Olympus Axion microscope (Olympus, Tokyo, Japan).

Flow cytometry. PE-CD133, FITC-CD44 (Biolegend, San Diego, CA, USA), LGR5, APC-CD271 antibodies were used for flow cytometry. Take CD133 for example, the expression of CD133 antigen on hybrids and parental CRC cells were performed by flow cytometry. Cells were stained with PE-conjugated monoclonal anti-human CD133 (Becton Dickinson, San Jose, CA, USA). Isotype control IgG-PE, served as a control. After stained $30 \mathrm{~min}$, samples were analysed by flow cytometry (FACS Calibur, BD Biosciences, San Jose, CA, USA) and data were analysed using CellQuest software and BD FACSDiva6.0 software (BD Biosciences). Intracellular staining flow cytometry followed the standard protocol provided by BD. CFSE (Biolegend, San Diego, CA, USA) and 7-AAD/Annexin V kit (eBioscience, Thermo Fisher Scientific, Darmstadt, Germany) were used to perform proliferation assay and cell apoptosis assay.

Selected isolation of MSCs from the co-culture system. Cell separation from co-culture system was performed using the

Figure 2. Co-culture system showed attenuate proliferation and viability under UV irradiation. (A) This is a representative figure of proliferation experiment. In total, $4 \times 10^{4} \mathrm{SW} 1116, \mathrm{HT} 29$ or DanG cells were seeded with or without (control group) $1 \times 10^{4} \mathrm{MSC}$ in 12 -well plate. In total, $10 \mathrm{~J} \mathrm{~cm}^{-2}$ irradiation was performed for $1 \mathrm{~h}$ and last for $6 \mathrm{~h}$ and total cell numbers in each well were counted at $12 \mathrm{~h}, 36 \mathrm{~h}$, and $72 \mathrm{~h}$ respectively. (B) CSFE assay of control and co-cultivation group. (C, D) 25, 50, 100, or 200 SW1116, SW620 cells were seeded in ultra-low attachment 24-well plates, respectively (control), or following by additional 25 bone marrow-derived mesenchymal stromal cells seeding in each well. Twenty-five more SW1116 cells were also seeded instead of $25 \mathrm{MSCs}$ as blank control. After $10 \mathrm{~J} \mathrm{~cm}^{-2}$ irradiation $1 \mathrm{~h}$ per $8 \mathrm{~h}$ for 8 days, cell colonies were counted on the 9th day. Independent experiments were repeated 2 3 times. Mean value were represented. (E) $6 \times 10^{6} \mathrm{SW} 1116$ cells were seeded in co-culture system (Supplementary Figure 2B), with or without $10^{6} \mathrm{MSC}$ cells seeding in the inserted well. $10 \mathrm{~J} \mathrm{~cm}{ }^{-2}$ irradiation was performed for $1 \mathrm{~h}$ and last for $8 \mathrm{~h}$ and total cell numbers in each well were counted at $24 \mathrm{~h}, 48 \mathrm{~h}, 72 \mathrm{~h}, 96 \mathrm{~h}$, and $120 \mathrm{~h}$, respectively. The colorectal cancer cells decreased more rapidly in the co-culture group than control group (SW1116 only) at the beginning $(0 \sim 96 \mathrm{~h})$ after irradiation, however, turned to be slower and stayed stable after $96 \mathrm{~h}$. (F) Co-culture model for MSCs and CRC. The $\mu$-Slide $2 \times 9$ well harbours two arrays of $3 \times 3$ square fields where cells can be cultivated independently within the small square or share the same growth medium within the total $3 \times 3$ square fields. After co-cultivation for $48 \mathrm{~h}$, flow cytometry showed more CD133 + CD44 + colorectal cancer stem cell-like cells than the control group. However, there were also more 7-AAD + dead cells compared with the control group. ${ }^{*} \mathrm{P}<0.05$. 
CD271 + MicroBeads isolation kit (Miltenyi Biotech) as recommended by the manufacturer. Separation occurs in a MACS Column, which induces a high-gradient magnetic field $(\sim 0.6$
Tesla) when placed in an AutoMACS Separator (Miltenyi Biotech). After the automatic sorting, CD271 + MSCs and CRC cells were separated in different falcon tubes for further analysis.
A

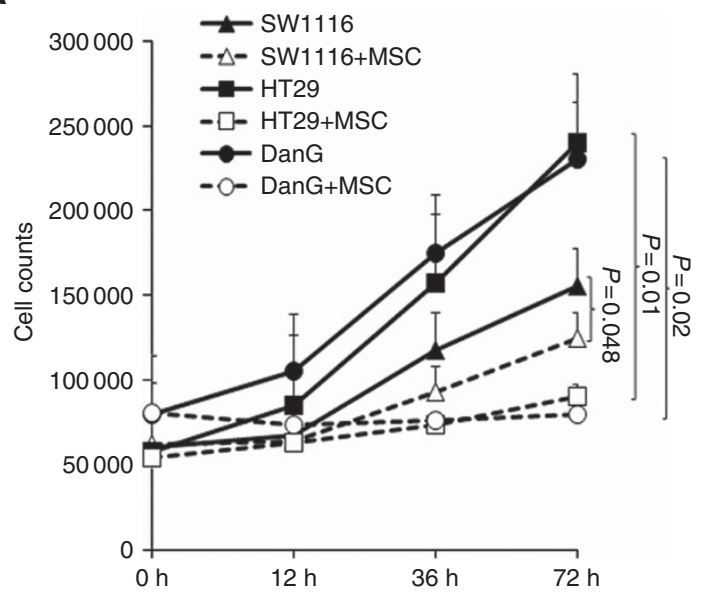

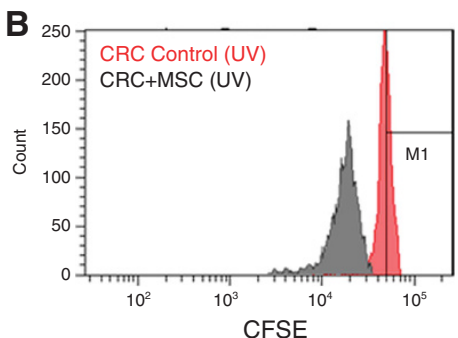

C SW620 (50 cells) SW620 (200 cells) SW1116 (200 cells)

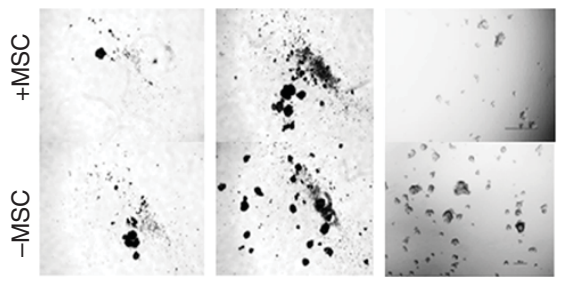

E
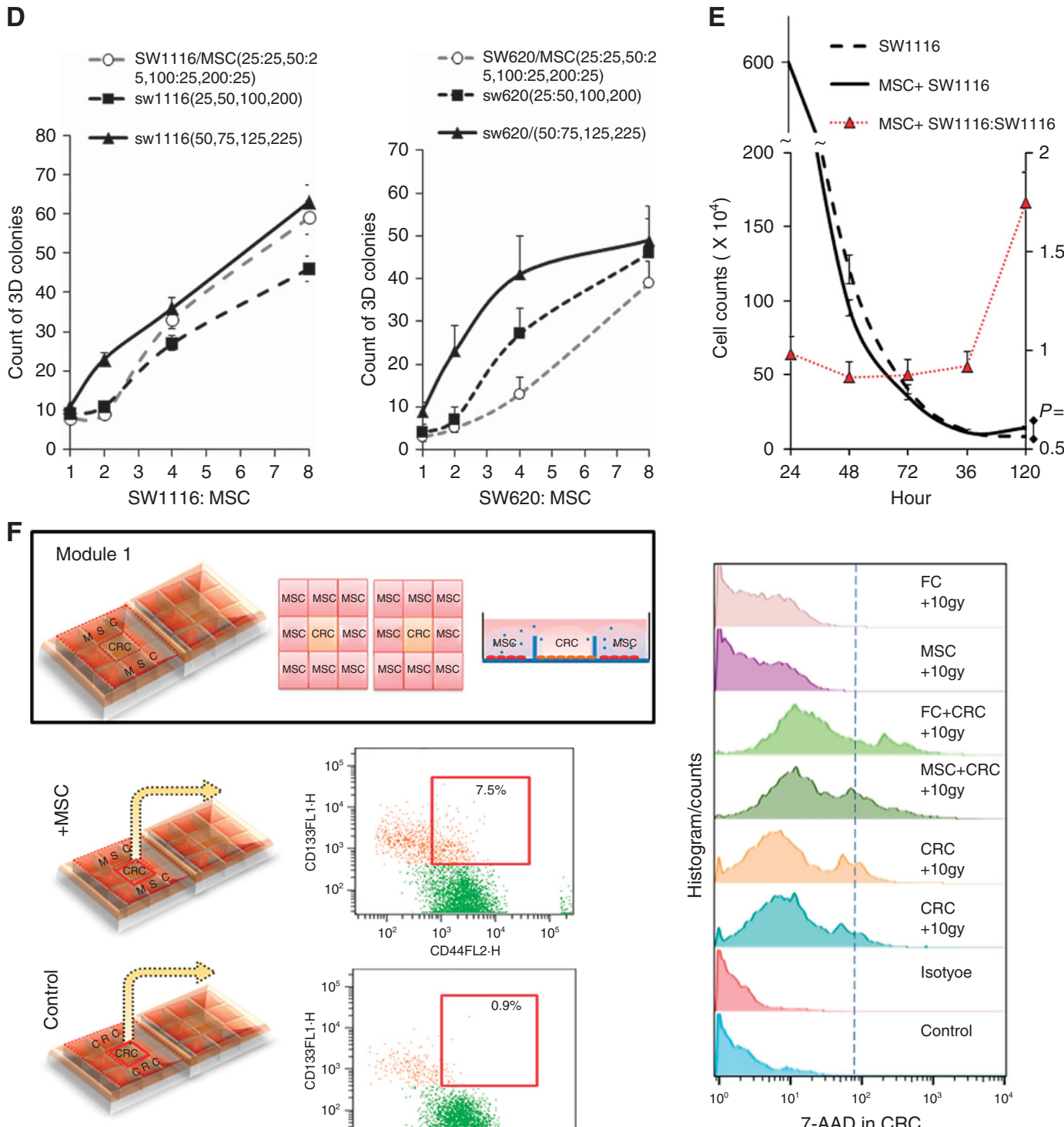
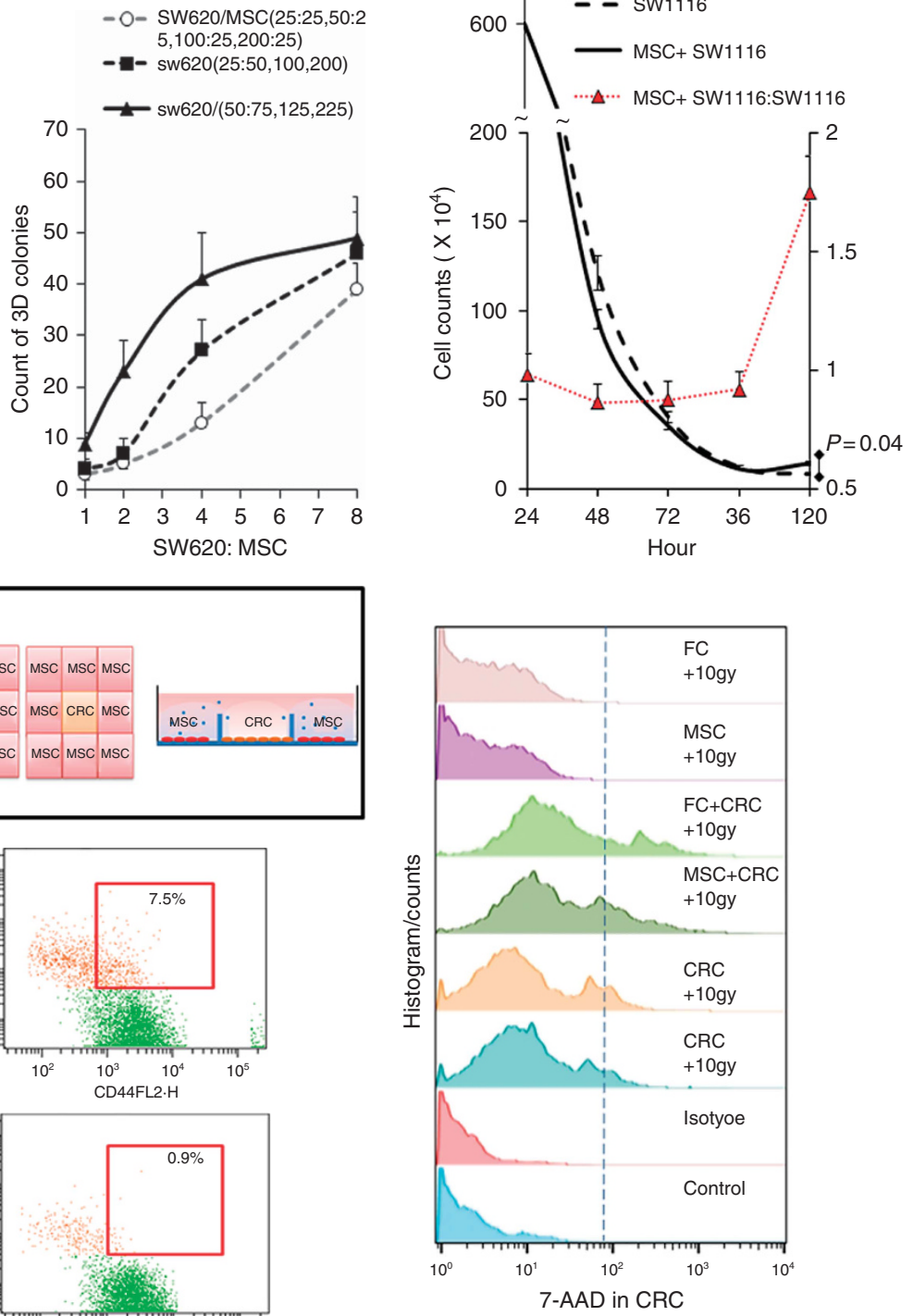
A

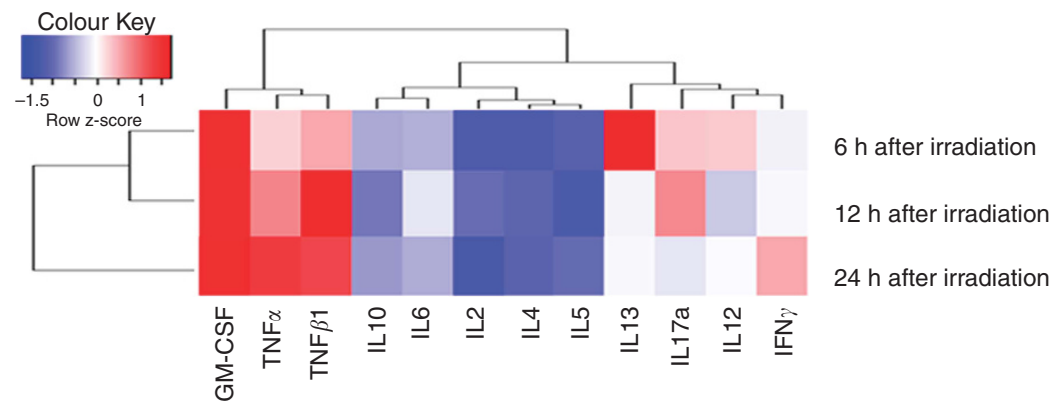

B

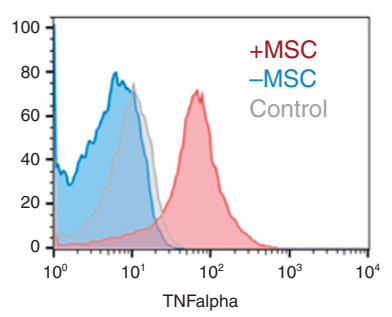

C

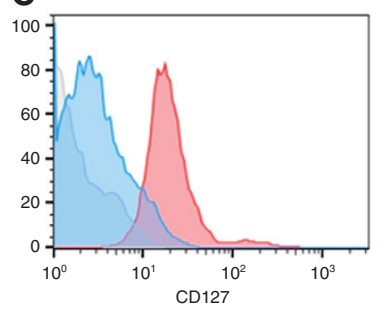

$\mathbf{F}$
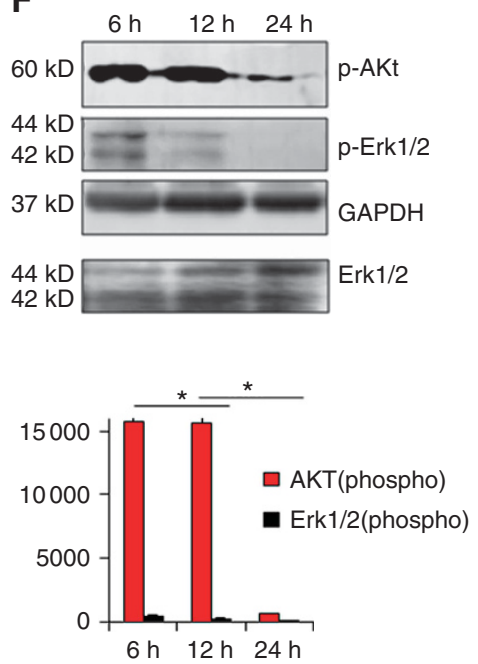

D

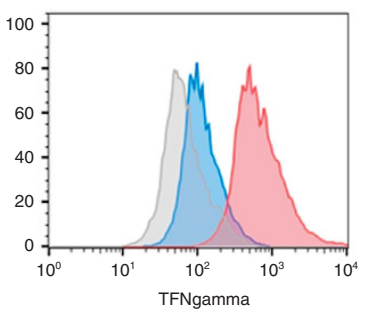

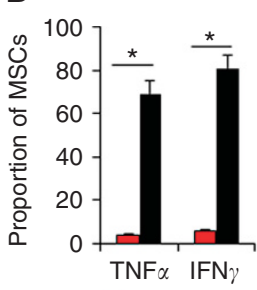

Before irradiation
MSC

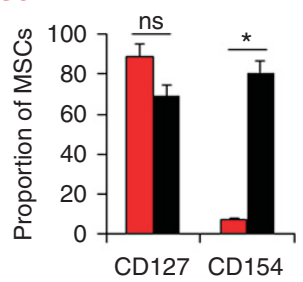

E
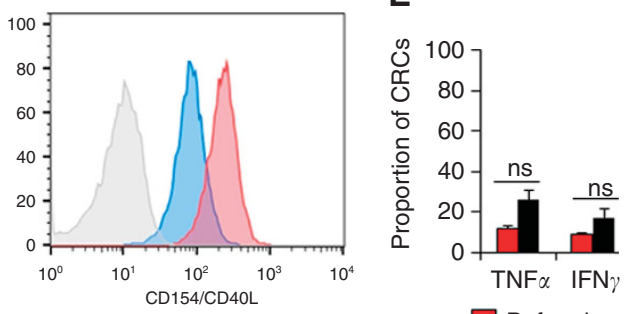

CRC

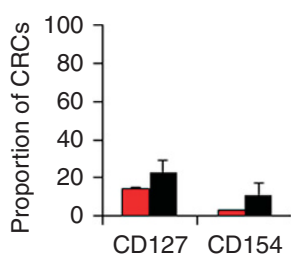

Before irradiation
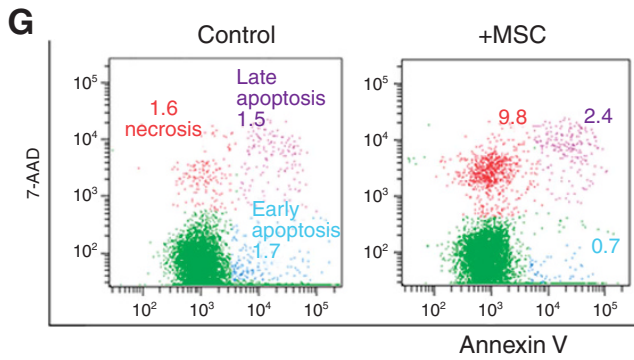

+anti-TNF $\alpha$, anti-IFN $\gamma$ cocktail
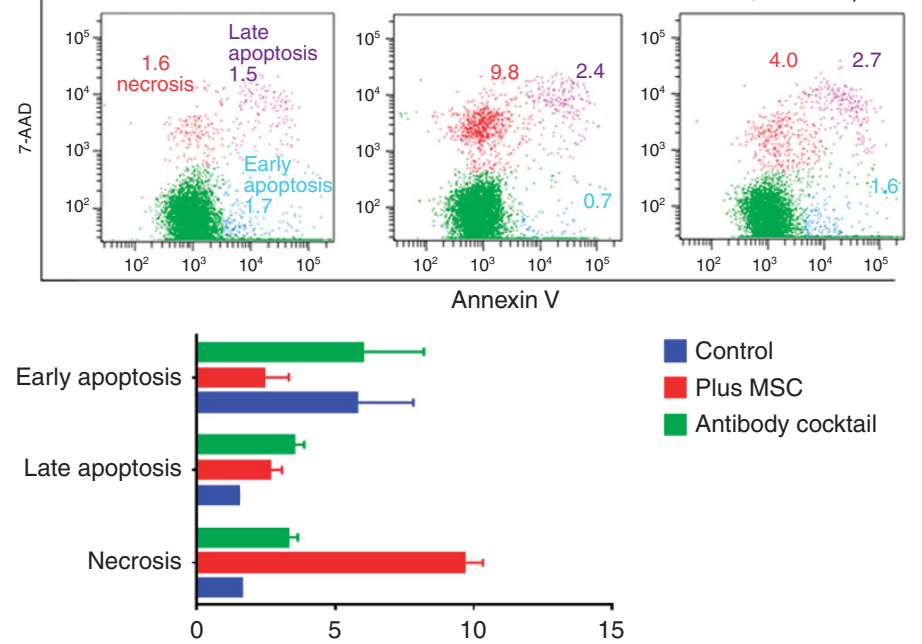

Control

Plus MSC

Antibody cocktail

Figure 3. Alteration of cytokine levels and protein expressions in MSCs or CRC cells from the co-cultivation system. (A) Supernatant from MSCs and CRC cells co-cultivation model were collected at $6 \mathrm{~h}, 12 \mathrm{~h}$, and $24 \mathrm{~h}$ after irradiation. ELISA array was performed, R studio was used for calculating and establishing the heat map. (B-E) To identify the origin of cytokines, MSCs, and CRCs were collected from the irradiated co-culture system, respectively. Elevated TNFa, IFN-gamma, and CD154 (CD4OL) were detected by flow cytometry in MSCs rather than CRC cells. Proportions of cells are shown in column; (D): expression of cytokines in MSC from co-cultivated model before and after irradiation; (E): cytokines expression of CRC cells in co-cultivated model before and after irradiation; (F): PI3K/AKT signal pathway protein p-Akt and p-Erk1/2 from colorectal cancer cells were significantly suppressed in the coculture system after $6 \mathrm{~h}, 12 \mathrm{~h}$, and $24 \mathrm{~h}$ UV irradiation; (G): after $10 \mathrm{~Gy}$ ionising irradiation and $24 \mathrm{~h}$ incubation, colorectal cancer cell line showed significantly increased necrosis rate, in the coculture model tested by 7 -AAD/ Annexin $V$ cell apoptosis assay. ${ }^{*} P<0.05$. 
Organoid culture. Fresh CRC tissue samples were cut into small pieces using a scalpel, washed with ice-cold PBS containing antibiotic $3 \sim 5$ times, and subsequently digested with $0.05 \%$ trypsin, $0.02 \%$ EDTA (Thermo Fisher Scientific, Waltham, MA, USA) for $12 \mathrm{~min}$ at $37^{\circ} \mathrm{C}$ with shaking every $15 \mathrm{~min}$. The remaining fragments were additionally treated with Collagenase NB 4G (SERVA Electrophoresis GmbH, Heidelberg, Germany) at $37^{\circ} \mathrm{C}$ for $20 \mathrm{~min}$. The pellet was re-suspended in $24 \mathrm{ml} 40 \%$ Percoll PLUS/Percoll, placed in 50-ml polystyrene conical centrifuge tube (BD Biosciences) and overlaid with $9 \mathrm{ml} 70 \%$ Percoll solution. Centrifuge immediately at $2500 \mathrm{rpm}$ (Eppendorf $5810 \mathrm{R}$ centrifuge) for $20 \mathrm{~min}$ (brake off), at room temperature. The cell fraction was carefully and gently collected above the interphase band (above $1.065 \mathrm{~g} \mathrm{ml}^{-1}$ ) by using a sterile Pasteur pipet, then pelleted at $1500 \mathrm{rpm}$ (Eppendorf, Hamburg, Germany) for $7 \mathrm{~min}$ at $4{ }^{\circ} \mathrm{C}$. The cell pellet was suspended with Matrigel (growth factor reduced; BD Biosciences) and dispensed into 48well culture plates $(25 \mathrm{ml}$ matrigel per well), which have also cover with single layer of MSC. The basal culture medium for human intestinal organoids was prepared as recently described (Fujii et al, 2016).

Analysis of publicly available data sets. To analyse CD271 mRNA expression in colorectal adenocarcinoma, we obtained the data from TCGA, by using www.cbioportal.org. Specifically, on the home page of the website, select 'Query', then, select 'Colorectal Adenocarcinoma (TCGA, Provisional)', enter CD271 (NGFR) gene in the 'enter gene set', download data from Plots and Survival data, click 'mRNA expression Z-score (all genes)' from Select Genomic Profiles, the NGFR mRNA $Z$-scores of 382 cases will appear. To analyse the effect of NGFR expression on prognostic of CRC patients, we generated Kaplan-Meier survival curve of CRC patients with low or high expression of NGFR by using PRISM.

Statistical analysis. All continuous values were expressed as mean \pm s.d. and all experiments were repeated three times. The results were subjected to a nonparametric Mann-Whitney $U$-test. A paired Student's $t$-test, unpaired $t$-test, two-way ANOVA were also used to analyse the intragroup and intergroup differences. All statistical analyses were done using GraphPad Prism7 (GraphPad Software Inc., La Jolla, CA, USA) and Stat View 5.0 for Windows (SAS Institute Inc., Cary, NC, USA). Student's $t$-test was also used to test differences in cell viability assays. A $P$-value $<0.05$ was considered statistically significant.

\section{RESULTS}

The proportion of CRC stem cell-like cells increased when cocultured with MSCs. CD271 is a biomarker for mesenchymal stem/stromal cells and follicular dendritic cells in the colorectal tumour site. In CRC specimens, the CD271 + MSC density (counts per $\left.\mathrm{mm}^{3}, n=20\right)$ was significantly higher $(P=0.037$, Figure $1 \mathrm{~A}$ and $B)$ than in adjacent normal tissues $(5 \sim 10 \mathrm{~cm}$ from the proximal tumour margin). Basing on TCGA publicly available data sets, it was found that high expression of NGFR (CD271) mRNA in the tumour tissues (mRNA $z$-score $>-0.3115$ ) was related to worse disease-free survival (DFS) (Figures 1C, $P=0.04$, $\mathrm{HR}=1.537,95 \% \mathrm{CI}: 1.014 \sim 2.332, n=382)$. This might suggest that high density of CD271 + MSC is relevant with a poor DFS rate of the patients. In in vitro experiment, CRC displayed the morphological characteristics of epithelial-mesenchymal transition after co-cultured with BM-MSCs for $72 \mathrm{~h}$ (Supplementary Figure 1A). To further identify whether MSC-CRC cell-cell adhesion was important for this alteration, three different coculture models were established. After $72 \mathrm{~h}$ co-cultivation in ibidi $\mu$-Dish (module 1, Figure 2F) and wedge-gap dish (module 2, Figure 1D), flow cytometry showed significantly elevated proportion of $\mathrm{CD} 133+$ cells $(48 \mathrm{~h}, 11 \pm 3.7$ vs $3 \pm 1.9 \%$, $P<0.05$ ), CD $133+$ CD $44+$ cells (Figure 1D, 72 h. $19.74 \pm 0.7426$ vs $11.73 \pm 0.9979, P<0.0001,95 \%$ CI $5.374 \sim 10.65$,) and Lgr5 + cells (Figure 1E, $72 \mathrm{~h}, \mathrm{CRC}+$ fibroblast, $75 \pm 10.8$ vs CRC + MSC, $60 \pm 3.8 v s$ MSC, $29 \pm 7$ ) in cancer cells from co-cultivation groups.

Cancer cells underwent epithelial-mesenchymal transition and MSC differentiated into mature cancer-associated fibroblasts (CAF) in the co-culture model. In the MSC-CRC wound-healing assay, MSCs showed greater mobility than CRC cells (Supplementary Figure 1B). Besides, MSCs exhibited a series of morphological changes, including elongated phenotype, reduced adhesion, and increased migration, which were normally observed in the differentiation process of MSCs to CAFs (Direkze et al, 2004). Immunofluorescence analysis of MSCs which were co-cultured with CRC cells for $48 \mathrm{~h}$ revealed upregulated expression of $\alpha$-SMA, whereas downregulated expression of desmin, suggesting the differentiation of MSCs to fibroblasts (Supplementary Figure 1C (a-f) D) (Wang et al, 2004). Meanwhile, immunofluorescence staining of CRC cells revealed up-regulated vimentin, fibronectin, snail as well as GFAP protein expression and downregulated E-cadherin expression, indicating the progression of epithelialmesenchymal transition (Supplementary Figure 1A, Figure1C, G-I).

CRC cells showed more attenuated proliferation and viability in the co-culture system than in the non-co-culture system under irradiation. Though it was found that high density of CD271+ MSC is relevant with a poor DFS rate of the CRC patients, however, radiotherapy was not taken into consideration. What is the function of MSCs when under radiation?

CRC cells $\left(4 \times 10^{4}\right.$ cells $)$ and MSCs $\left(1 \times 10^{4}\right.$ cells $)$ were seeded and cultured in module 2 (module 2, Figure 1D), with CRC cells $\left(4 \times 10^{4}\right.$ cells $)$ cultured alone as the control group. Cells were then irradiated with $10 \mathrm{~J} \mathrm{~cm}^{-2}$ irradiation for $1 \mathrm{~h}$ per $8 \mathrm{~h}$, lasting for $72 \mathrm{~h}$. Viable CRC cells and MSCs in each group were collected and counted every $12 \mathrm{~h}$, respectively. Proliferation assays were performed in CRC cells. CRC cells from co-culture group showed a significantly attenuated proliferation capability (Figure 2A and B).

In the $3 \mathrm{D}$ colony formation assay, different numbers of $\mathrm{CRC}$ cells $(25,50,100$, and 200 cells) were seeded in ultra-low attachment plates as the blank control group, additional 25 MSCs were seed to each well to set up the co-culture group, making the final CRC: MSC ratio 1:1, 2:1, 4:1, and 8:1. The negative control group was established by using additional 25 CRC cells instead of 25 MSCs. Cells were then treated with $10 \mathrm{~J} \mathrm{~cm}^{-2}$ irradiation for $1 \mathrm{~h}$ per $8 \mathrm{~h}$, lasting for 8 days. Cell colonies were counted on the 9 th day (Figure 2C). The negative control group exhibited a significantly enhanced colony formation capability $\left(p_{\text {sw620 }}=0.035\right.$, $\left.p_{\text {sw1116 }}=0.027, p_{\mathrm{HT} 29}=0.043\right)$, especially with CRC:MSC ratio within 2:1 4:1 (Figure 2D). Based on these results, we suggest that the MSCs impaired the proliferation and colony formation capability of CRC cells under irradiation. Next, we use module 2, which can include more cells to verify the finding.

Specifically, $6 \times 10^{6} \mathrm{CRC}$ cells and $1 \times 10^{6}$ MSC cells were seeded in the inner well and outer well of the co-culture system, respectively (module 2). The control group was established by seeding only the same amount of CRC cells in the inner well. Cells were treated with $10 \mathrm{~J} \mathrm{~cm}^{-2}$ irradiation for $1 \mathrm{~h}$ every $8 \mathrm{~h}$. Cell counts in each well were calculated at $24 \mathrm{~h}, 48 \mathrm{~h}, 72 \mathrm{~h}, 96 \mathrm{~h}$, and $120 \mathrm{~h}$, respectively. The result is consistent with former results. Especially within $96 \mathrm{~h}, \mathrm{CRC}$ cell counts declined more rapidly in the co-culture group than CRC cells alone (Figure 2E). Intriguingly, the number of viable CRC cells from the co-culture system stayed stable after $96 \mathrm{~h}$. However, the number of $\mathrm{C} \quad \mathrm{xRC}$ cells in the control group was still decreasing (Figure 2E, Supplementary Figure 1E). Accordingly, this could be owing to that the MSCinduced part of cancer cells to maintain/gain stemness at the early phase of irradiation, thereafter those cancer stem cells-like cells 
A
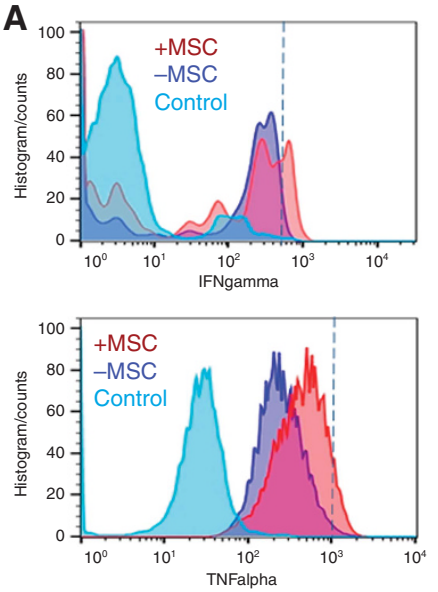

B

\begin{tabular}{ccc}
$\mathrm{CRC}$ & $\mathrm{CRC}$ & $\mathrm{CRC}$ \\
(control) & $(\mathrm{MSC}+\mathrm{CRC})$ & (Fibroblast+CRC) \\
\hline
\end{tabular}

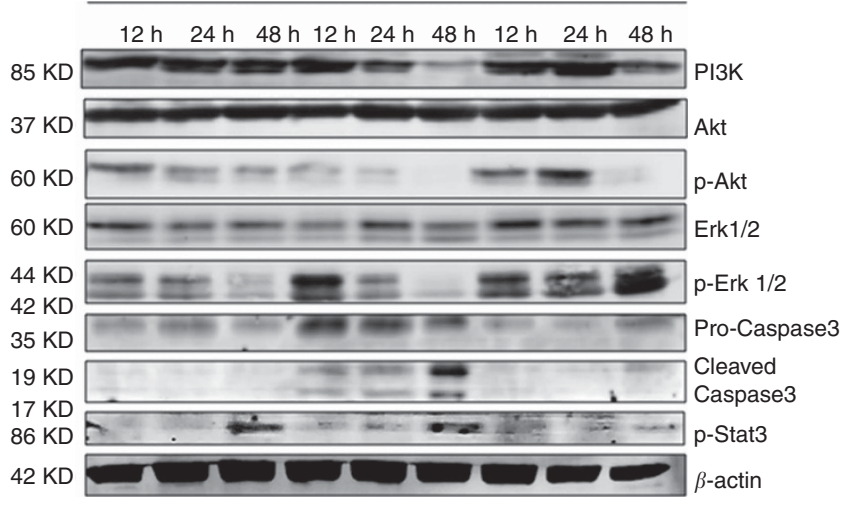

\section{c}

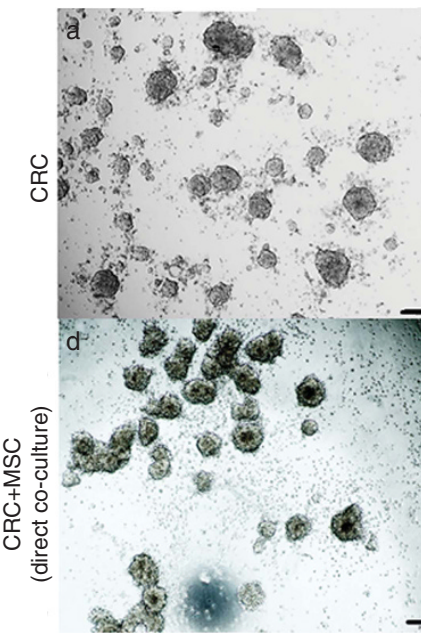

b
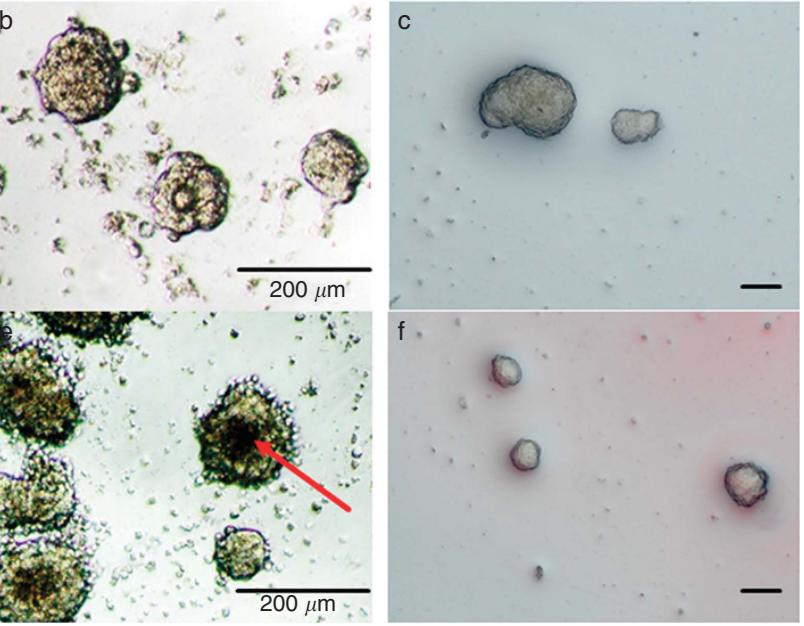

D

$\mathrm{CRC}+\mathrm{MSC}$

(direct co-culture)

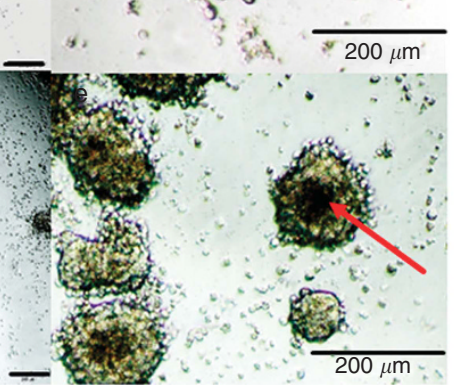

$\mathrm{CRC}+\mathrm{MSC}$

(indirect co-culture)

CRC
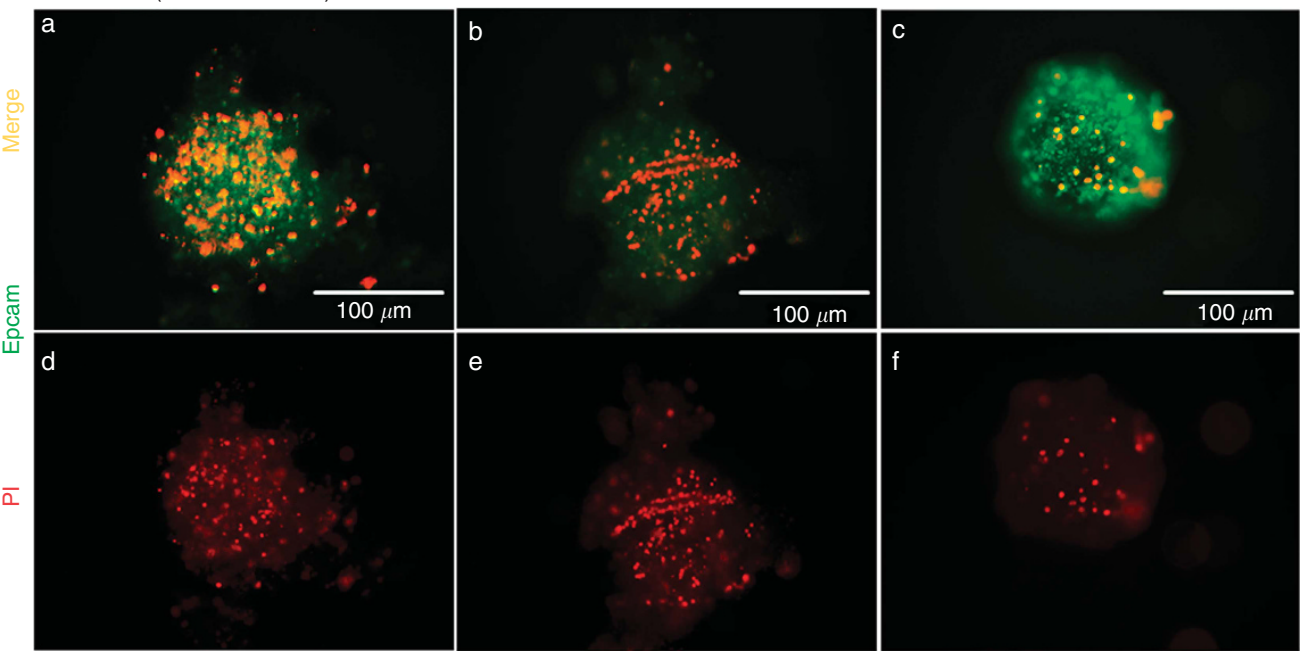

Figure 4. Co-cultivation showed increased cell death and suppression of AKT signal pathway of colorectal cancer cells under ionising irradiation. (A) lonising irradiation could induce TNF $\alpha$ and IFN5 secretion by MSC in the co-cultivated system. (B) Colorectal cancer cell ERK and AKT signalling pathways were suppressed in the co-cultivated system, meanwhile, cleaved caspase 3 , and p-Stat3 in CRC cells were activated in CRC + MSC co-culture group. (C) The same number of 3D spheroids (CRC cells and CRC cells + MSCs) were transferred into an ultra-low attachment plate and treated with $10 \mathrm{~J} \mathrm{~cm}^{-2}$ irradiation for $1 \mathrm{~h}$ in every $6 \mathrm{~h}$. Dark cores (red arrow), which were reported to be dead cells, could be observed in the co-culture group. Tumour organoids were co-cultivated with or without MSCs, the volumes of tumour organoids turned to be smaller in the cocultivation group ( $f$, a single layer of MSC was seeded below the Matrigel layer) compared with CRC without MSCs feeding after irradiation. (D) To further confirm the cytotoxicity effect of MSC under irradiation, PI staining was performed on two co-culture models (direct CRC cells-MSCs contact and indirect co-cultivation), as well as colorectal cancer spheroids. the co-cultivation group, both direct co-cultivation and indirect co-cultivation showed more dead cells under irradiation even in 3D culture condition. 


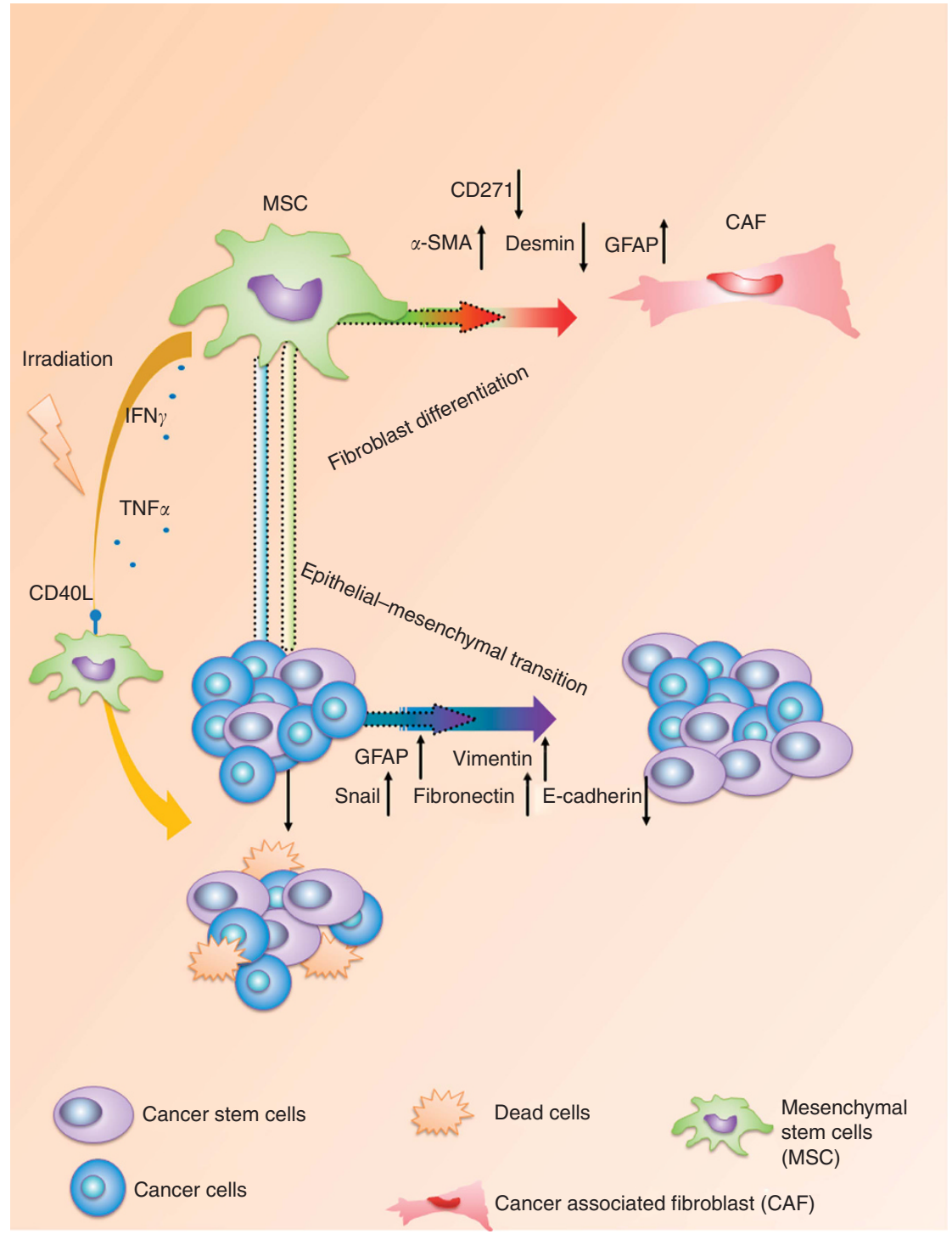

Figure 5. Schematic representation of colorectal cancer cells apoptosis induced by irradiation treated bone marrow-derived mesenchymal stromal cells.

could be resistant to irradiation. Subsequently, the hypothesis was further approved by stem cell staining (CRC + MSC vs CRC Control: $\quad 7.533 \pm 0.48$ vs $0.95 \pm 0.23 \%, \quad P<0.0001, \quad 95 \% \quad \mathrm{CI}$, $-7.703 \sim-5.453)$ and 7 -AAD live/dead cell staining via flow cytometry (Figure 2F).

MSCs secrete IFN $\gamma$, TNF $\alpha$ when co-cultured with CRC cell under irradiation. To investigate the reason behind the finding, we supposed that cytokine alteration induced by MSCs might affect the CRC cells. To verify the hypotheses, cells grown in the coculture system was treated with $10 \mathrm{~J} \mathrm{~cm}^{-2}$ irradiation for $1 \mathrm{~h}$ in every $6 \mathrm{~h}$. The supernatant was collected afterward at $6 \mathrm{~h}, 12 \mathrm{~h}$, and $24 \mathrm{~h}$, respectively. ELISA array was performed with the supernatant and the result was presented in Figure $3 \mathrm{~A}$. It reveals that the supernatant from the co-culture system contained increased concentration of GM-CSF, which was reported by others. Besides, elevated TGF- $\beta 1, \mathrm{IFN} \gamma$, and TNF $\alpha$ were also detected. In contrast, IL13 decreased significantly after the ultraviolet radiation (UV) irradiation. To investigate the cell origin of TNF $\alpha$ or IFN $\gamma$, flow cytometer analysis was performed. We found that it is MSC rather than CRC cell that is responsible for the secretion of TNF $\alpha$, IFN $\gamma$, and expression of CD154 (also known as CD40L), which can induce cytotoxicity against CRC (Figure 3B-E).
Phosphorylated AKT (p-Akt) and phosphorylated Erk1/2 were suppressed in CRC cells from the co-cultured system. Next, we investigate the change of signal pathways, which are involved in the cell proliferation by western blot. Specifically, the result revealed that $\mathrm{p}$-Akt and $\mathrm{p}$-Erk1/2, which are important protein in $\mathrm{PI} 3 \mathrm{~K} / \mathrm{AKT}$ signal pathway, were significantly suppressed in CRC cells when co-cultured with MSCs under UV irradiation conditions (Figure 3F). Taken together, suppression of p-Akt and Erk1/2 in CRC cells, when incubated with MSC under irradiation, contributes to the arrest of the cell proliferation and cell death.

CRC cells showed increased apoptosis and suppressed AKT signal pathway in the co-culture system under ionising irradiation. Subsequently, we investigate the cell apoptosis and AKT signal pathway in CRC cells in the co-culture system. Specifically, CRC cells and MSCs were co-cultured and irradiated under same conditions as described before. Cell death and cell apoptosis assay showed significantly increased cell death of CRC cells, especially necrosis of cells in co-culture group. For instance, SW620 isolated from the co-culture module 2 display significantly higher proportion of necrotic cells $(9.7 \pm 1.2 v s 1.6 \pm 0.1 \%)$ and late apoptotic cells $(2.6 \pm 0.8$ vs $1.5 \pm 0.05 \%)$ after irradiation 
$(P=0.0012)$. Despite the heterogeneity among different cancer cell lines, total cell death and necrosis rate of CRC cells were increased significantly in the co-culture group (Figure 3G). In consistent with the result of UV irradiation, ionising irradiation could also induce TNF $\alpha$ and IFN $\gamma$ secretion by MSC in the co-culture system (TNF $\alpha$ : 13.6 vs $1.2 \%, P<0.05$; IFN $\gamma 22.1$ vs $4.6 \%, P<0.01$, Figure $4 \mathrm{~A}$ ). When the co-culture system was treated with TNF $\alpha$ and IFN $\gamma$ neutralising antibodies, CRC cells displayed attenuated cell death rate $(P=0.03$, Figure $3 \mathrm{G})$. Moreover, ERK and AKT signalling pathways were suppressed while apoptosis pathway was activated in CRC cells. Interestingly, p-Stat3 was also activated in CRC cells, which might be the result of feedback regulation to rescue CRC cells from death (Figure 4B).

CRC cells showed increased apoptosis in the $3 \mathrm{D}$ co-culture system under ionising irradiation. Afterward, the cytotoxicity of MSC under ionising irradiation was performed in the $3 \mathrm{D}$ coculture system. CRC cells were co-cultivated with or without MSC in the hanging-drop plates to form 3D spheroids (direct cocultured). The same number of spheroids were then transferred into a 96-well ultra-low attachment plate and treated with $10 \mathrm{~J} \mathrm{~cm}^{-2}$ irradiation for $1 \mathrm{~h}$ in every $6 \mathrm{~h}$. Dark cores, which were reported to be dead cells, could be observed in the co-culture group (Figure 4C). Tumour organoids derived from three patients were also sub-cultured with or without MSC (see Method), the volumes of tumour organoids turned to be smaller in the co-cultivation group (Figure $4 \mathrm{~F}$ ) after irradiation. To further confirm the cytotoxicity effect of MSC under irradiation, immunofluorescence staining was performed on two co-culture models (direct and indirect), as well as CRC spheroids. In consistent with our hypothesis, the co-cultivation group showed more dead cells under irradiation even in $3 \mathrm{D}$ condition (Figure 4D).

\section{DISCUSSION}

Radiation therapy could render tumour cells visible to the immune system of patients. In addition to the direct effects of radiation, the ensuing immune response orchestrates the expression of inflammatory mediators and cytokines, which act on local milieu and neighbouring tumour cells (Sologuren et al, 2014). Although MSCs are not originally identified as immune cells, MSCs possesse various immune regulatory capacities and are pivotal components in the tumour microenvironment, being able to home and infiltrate into the tumour stroma. Up to date, results of previous studies are controversial about its biological interaction with CRC cells, particularly in terms of promotion versus inhibition of tumour progress (Guan and Chen, 2013).

In normal tissues, MSCs were observed to be radiationprotective through its well-known ability of regenerative functions after ionising radiation (Gao et al, 2012; Li et al, 2013; Nicolay et al, 2015; Wilson et al, 2015). It was proposed that MSC may also be protective in a similar way for CRC cells after radiation. Thereafter, some research groups found that after the treatment of MSCconditioned medium, breast cancer cells could exhibit elevated proliferation capability as well as radiation-resistance, owing to the high levels of insulin-like growth factor-1 in the medium (Yang et al, 2014). Meanwhile, evidence was also provided that MSC could induce both inflammatory and immune suppressive microenvironment (Eterno et al, 2014), indicating that the cytokines, e.g. G-CSF, IL1a, and TNF $\alpha$ etc., were tightly regulated by environmental challenges (Zhukareva et al, 2010).

In contrast, most recent investigations demonstrated that MSCs were able to inhibit tumour growth by apoptosis induction (Han et al, 2014). Moreover, it seems that MSCs, in combination with irradiation, were able to enhance the systematic anti-tumour effect of ionising radiation and thus synergistically increase the efficiency of radiotherapy (de Araújo Farias et al, 2015). One of the reasons might be that radiation-induced acute damage to MSCs and a perpetual cascade of cytokines triggered the recruitment of immune cells (Wirsdörfer and Jendrossek, 2016). Intriguingly, lower doses of irradiation could selectively stimulate the proliferation of MSCs but not tumour cells in vitro via the activation of MAPK/ERK signalling pathway (Liang et al, 2011). In addition, MSCs could also possess superior antioxidant ROS-scavenging capacity and more active DNA double-strand break repair systems to facilitate their radioresistance (Chen et al, 2006). In the present study, we demonstrated that, under a low dose of radiation, MSCs might improve the anticancer responses by releasing various cytokines such as IFN $\gamma$ and $\mathrm{TNF} \alpha$ and expressing upregulated $\mathrm{CD} 154$, and attenuated the proliferative activity and viability of CRC cells, producing a potent cytotoxic synergistic effect on CRC cells. Besides, other groups have found that MSC can express iNOS, secrete IL-12, IL-2, and other foreign gene-encoded cytokines to inhibit tumour progress or the proliferation of other cells (Nakamura et al, 2004; Xiang et al, 2009; Gao et al, 2010; Zinöcker and Vaage, 2012; Jeong et al, 2015).

Cell death was just one aspect of cancer biology. Another vital aspect was the invasion of the cells, which is directly related to metastasis. To evaluate whether X-ray irradiation lead to increased metastases, the transwell invasion assay was performed. Though the CRC and MSC co-culture group showed stronger invasive capability, there was no difference between CRC + MSC group and CRC group when cultivated under irradiation.

Furthermore, recent data also suggested that MSCs exhibited potentials for inhibiting tumour proliferation or spread through cell cycling arresting and cell death-related signalling pathways activation (Chang et al, 2015). For example, Khakoo et al reported that reducing tumour cell growth could be observed ex vivo when treated with human bone marrow MSC by Akt activity inhibition of tumour cells (Khakoo et al, 2006). In the present study, irradiation on the co-culture system induced the cleavage of caspase3, and attenuated the PI3K/ AKT as well as ERK in cancer cells. Similarly, it was reported that MSC associated anticancer effect was mainly by suppressing PI3K/Akt signalling pathway and subsequently increasing the protein level of cell death factors (Ma et al, 2012). Specifically, combination of MSCs and radiations resulted in the cleavages of caspase $9 / 3$, increased phosphorylation of JNK and decreased phosphorylation of PI3K/AKT and ERK in cancer cells. Suppression of PI3K/Akt signalling cascades could lead to the blockade of both cell cycle progression and cell growth during CRC development. Han et al (2014) reported that JNK inhibition reversed the apoptotic ability of MSCs to cleave caspase $9 / 3$ in prostate cancer cells, indicating that the JNK pathway might also be activated when PI3K was suppressed. Aikin et al (2004) claimed that suppression of PI3K was the reason of increased JNK phosphorylation and cell death. Many mechanisms might be involved in the suppression of PI3K/Akt signalling pathway, e.g., cytokines (IGF-1, TNF $\alpha$ et al) (Liu et al, 2017), PTEN overexpression, and miRNA. Concerning the cytokines, though it was reported that $\mathrm{TNF} \alpha$ could inhibit the apoptosis of several cancer cells by inducing the phosphorylation of Akt at both Ser473 and Thr308, the switch of promoting or inhibiting apoptosis effect was mainly dependent on the concentration of TNF $\alpha$ (Sandra et al, 2002). Other mechanisms included ROS-induced PI3K/Akt signalling pathway activation and radiation-associated bystander effect of MSCs on CRCs. Radiation-induced bystander effect is to descript the phenomenon that cells which exposed to irradiation could communicate their DNA damage response condition to bystander cells, which have not been directly irradiated. Cytokines induced ROS-production (Schaue et al, 2012), Activation of NF-çB signalling pathway, and NF-çB induced enzymatic systems like iNOS were suggested to be the molecular underpinnings of this bystander effect (Han et al, 2003). 
In co-culture experiments without UV irradiation, we found that MSCs prompted the epithelial-mesenchymal-transition and CRC cell stemness. Similarly, Xue JG et al reported that co-culture of gastric cancer cells and umbilical cord MSCs increased the expression of stemness factors and EMT markers, such as $\mathrm{N}$-cadherin, Vimentin, $\alpha$-SMA, and fibroblast activation protein, in gastric cancer cells (Direkze et al, 2004; Xue et al, 2015) Though MSC was important in promoting an inflammatory and immune suppression microenvironment, the function of MSCs was also interfered by the tumour microenvironment. In this study, we also observed an elevated expression of TGF- $\beta$, particularly at the early phase of post-irradiation, in the supernatant of the co-culture model. We verified that elevated expressions of TGF- $\beta$ could promote the differentiation of MSCs to CAFs (Wang et al, 2004; Quante et al, 2011). Similarly, other groups have reported that TGF- $\beta$ can stimulate hypomethylation of MSCs and induce gene expression profiles alterations towards myofibroblast signature-expressing biomarkers. However, the limitation of this study is lack of in vivo perspective. Concerning preclinical situation, the study from de Araújo Farias et al might give a clue. They reported that in vitro MSCs are a source of anti-tumour cytokines after a low dose of irradiation, MSCs decreased the proliferative activity of tumour cells, producing a potent cytotoxic synergistic effect on tumour cells (Direkze et al, 2004; de Araújo Farias et al, 2015; Xue et al, 2015).

It was recently demonstrated that radiations might induce senescence of MSCs which affect the functions. Consequently, senescent cells could block the proliferation of cancer cells and induced apoptosis (Özcan et al, 2015, 2016; Alessio et al, 2017). Thus, we performed the acid $\beta$-galactosidase assay. Cells were irradiated with the total dose of $10 \mathrm{~Gy}$. We found the proportion of senescent MSCs was increasing after the irradiation $(P=0.037)$ (Supplementary Figure 2A). However, when we incubated the cancer cells with the conditional medium from control or senescent MSC, there was no significant effect on CRC cells by acid $\beta$-galactosidase staining. Secretomes and exosomes had an important role in anti-tumour activities. However, in the present study, the effect was not significant. It might be owing to the effect becoming impaired when secretomes were collected from senescent cells previously in contact with cancer cells as reported before (Özcan et al, 2015; Alessio et al, 2017).

Concerning the limitations of this study, the in-vivo experiment needs to be further performed to verify not only the therapeutic achievement but also bystander effects of MSCs administration in CRC patients. In addition, concerning the similarities and differences between of UV-C and X-ray in the present study, for UV radiation, the main damages are on the same DNA strand. However, X-rays induced both single and double strand breaks. Another difference is that the X-rays are more penetrating, which is also why they are used in radiation oncology. However, the similarities could be found even at the beginning of the signalling response cascade. Both these damages allow the phosphorylation of histone variant $2 \mathrm{AX}$ and form characteristic 'repair foci'. UV and ionising irradiation were used together in lots of studies (Aszterbaum et al, 1999). Because both UV and ionising radiation (IR) produce oxidised bases DNA damage, they could also elicit complex cellular responses involving several similar signalling pathways, for example, NF-çB signalling pathway, MAPK signalling pathway, PI3K/AKT signalling pathway, and ROS-associated signalling pathways (Rieger and Chu, 2004).

Because MSC differentiated into CAF during the cocultivation with tumour cells, it is important to examine the BM-MSCs as a function of time: before and after this differentiation occurs. It was reported that the CAF associated genes such as SDF-1, CCL2, MMP9, and PDGFRB were upregulated in the 30-day tumour conditional media exposed MSC. Most of the top 25 upregulated genes were involved in glycoprotein and binding process and in cellular metabolism. (Mishra et al, 2008). Those CAF-like cells could stimulate tumour survival and proliferation, angiogenesis, and metastatic spread in xenograft models (Guilloton et al, 2012).

Concerning the clinical setting, the time period might change the treatment strategy. In brief, it took more or less 5-6 weeks. However, the functional consequence of MSC plus radiation is controversial. The detailed properties of radiation-surviving endogenous MSCs are not well documented in human and animal studies. It is generally agreed that the physiologic properties of surviving MSCs after a life-threatening dose of radiation are more likely to differ significantly from those before radiation exposure, despite their having an active DNA damage responding pathway. Even the anti-fibrotic or pro-fibrotic effect is still not certain, from one hand, MSC could stimulate the cell proliferation of fibroblast and modulate relevant soluble mediators and proteinases after external radiation (Haubner et al, 2015), on the other hand, the post-irradiation injection of MSC could induce host secretion of HGF and PGE2 to control the activation of fibroblasts. To summary, the effects differ a lot owing to the various models and dose setting. Thus, to establish a standard, more clinically relevant model to evaluate the effect of MSC as well as radiation is essential. The present study is just offering evidence from one perspective.

Taken together, this study provided a possibility to enhance the anti-tumour effect of radiotherapy by utilising MSCs treatment. (Figure 5). When irradiated with low-dose irradiation, BM-MSCs show an anti-tumour effect by secreting cytokines like TNF- $\alpha$, IFN$\gamma$ that lead to the inhibition of proliferation and induction of apoptosis of CRC cells. In addition, suppression of PI3K/AKT signal pathway proteins p-Akt and Erk1/2 in CRC cells also contributed to the arrest of cancer cell proliferation and cell death under irradiation when incubated with MSC.

\section{ACKNOWLEDGEMENTS}

This study was supported by China Scholarship Council (201306230127 to Feng H). This study was also supported by National Natural Science Foundation of China (81201625), Shanghai National Science Foundation (124119a0900, 16ZR1421300), and Biomedical Engineering Cross Foundation of Shanghai Jiaotong University (YG2013MS32).

CONFLICT OF INTEREST

The authors declare no conflict of interest

\section{REFERENCES}

Aikin R, Maysinger D, Rosenberg L (2004) Cross-talk between phosphatidylinositol 3-kinase/AKT and c-jun NH2-terminal kinase mediates survival of isolated human islets. Endocrinology 145(10): pp 4522-4531.

Alessio N, Esposito G, Galano G, De Rosa R, Anello P, Peluso G, Tabocchini MA, Galderisi U (2017) Irradiation of mesenchymal stromal cells with low and high doses of alpha particles induces senescence and/or apoptosis. J Cell Biochem 118(9): 2993-3002.

Alessio N, Capasso S, Di Bernardo G, Cappabianca S, Casale F, Calarco A, Cipollaro M, Peluso G, Galderisi U (2017) Mesenchymal stromal cells having inactivated RB1 survive following low irradiation and accumulate damaged DNA: Hints for side effects following radiotherapy. Cell Cycle 16(3): 251-258.

Alessio N, Del Gaudio S, Capasso S, Di Bernardo G, Cappabianca S, Cipollaro M, Peluso G, Galderisi U (2015) Low dose radiation induced senescence of human mesenchymal stromal cells and impaired the autophagy process. Oncotarget 6(10): pp8155.

Aszterbaum M, Epstein J, Oro A, Douglas V, LeBoit PE, Scott MP, Epstein EH (1999) Ultraviolet and ionizing radiation enhance the growth of BCCs and 
trichoblastomas in patched heterozygous knockout mice. Nat Med 5(11): 1285-1291.

Brozyna A, Zbytek B, Granese J, Carlson JA, Ross J, Slominski A (2007) Mechanism of UV-related carcinogenesis and its contribution to nevi/ melanoma. Expert Rev Dermatol 2(4): pp451-469.

Chang PY, Qu YQ, Wang J, Dong LH (2015) The potential of mesenchymal stem cells in the management of radiation enteropathy. Cell Death Dis 6(8): ppe1840.

Chen F, Zhuang X, Lin L, Yu P, Wang Y, Shi Y, Hu G, Sun Y (2015) New horizons in tumor microenvironment biology: challenges and opportunities. BMC Med 13(1): pp45.

Chen MF, Lin CT, Chen WC, Yang CT, Chen CC, Liao SK, Liu JM, Lu CH, Lee KD (2006) The sensitivity of human mesenchymal stem cells to ionizing radiation. Int J Radiat Oncol Biol Phys 66(1): pp244-253.

Deacon DH, Hogan KT, Swanson EM, Chianese-Bullock KA, Denlinger CE, Czarkowski AR, Schrecengost RS, Patterson JW, Teague MW, Slingluff CL (2008) The use of gamma-irradiation and ultraviolet-irradiation in the preparation of human melanoma cells for use in autologous whole-cell vaccines. BMC Cancer 8(1): pp360.

de Araújo Farias V, O'Valle F, Lerma BA, de Almodóvar CR, López-Peñalver JJ, Nieto A, Santos A, Fernández BI, Guerra-Librero A, Ruiz-Ruiz MC, Guirado D (2015) Human mesenchymal stem cells enhance the systemic effects of radiotherapy. Oncotarget 6(31): pp31164.

Direkze NC, Hodivala-Dilke K, Jeffery R, Hunt T, Poulsom R, Oukrif D, Alison MR, Wright NA (2004) Bone marrow contribution to tumorassociated myofibroblasts and fibroblasts. Cancer Res 64(23): pp84928495.

Eterno V, Zambelli A, Pavesi L, Villani L, Zanini V, Petrolo G, Manera S, Tuscano A, Amato A (2014) Adipose-derived Mesenchymal Stem Cells (ASCs) may favour breast cancer recurrence via HGF/c-Met signaling. Oncotarget 5(3): pp613.

Fazel R, Krumholz HM, Wang Y, Ross JS, Chen J, Ting HH, Shah ND, Nasir K, Einstein AJ, Nallamothu BK (2009) Exposure to low-dose ionizing radiation from medical imaging procedures. $N$ Engl J Med 361(9): pp849-857.

Fujii M, Shimokawa M, Date S, Takano A, Matano M, Nanki K, Ohta Y, Toshimitsu K, Nakazato Y, Kawasaki K, Uraoka T (2016) A colorectal tumor organoid library demonstrates progressive loss of niche factor requirements during tumorigenesis. Cell Stem Cell 18(6): pp827-838.

Fujita M, Yamada S, Imai T (2015) Irradiation induces diverse changes in invasive potential in cancer lines. Semin Cancer Biol 35: 45-52.

Galderisi U, Giordano A (2014) The gap between the physiological and therapeutic roles of mesenchymal stem cells. Med Res Rev 34(5): pp1100-1126.

Gao P, Ding Q, Wu Z, Jiang H, Fang Z (2010) Therapeutic potential of human mesenchymal stem cells producing IL-12 in a mouse xenograft model of renal cell carcinoma. Cancer Lett 290(2): pp157-166.

Gao Z, Zhang Q, Han Y, Cheng X, Lu Y, Fan L, Wu Z (2012) Mesenchymal stromal cell-conditioned medium prevents radiation-induced small intestine injury in mice. Cytotherapy 14(3): pp267-273.

Guan J, Chen J (2013) Mesenchymal stem cells in the tumor microenvironment. Biomed Rep 1(4): pp517-521.

Guilloton F, Caron G, Ménard C, Pangault C, Amé-Thomas P, Dulong J, De Vos J, Rossille D, Henry C, Lamy T, Fouquet O (2012) Mesenchymal stromal cells orchestrate follicular lymphoma cell niche through the CCL2-dependent recruitment and polarization of monocytes. Blood 119(11): pp2556-2567.

Gullo CA, Hwang WY, Poh CK, Au M, Cow G, Teoh G (2008) Use of ultraviolet-light irradiated multiple myeloma cells as immunogens to generate tumor-specific cytolytic T lymphocytes. J Immune Based Ther Vaccines 6(1): 2.

Han D, Antunes F, Canali R, Rettori D, Cadenas E (2003) Voltage-dependent anion channels control the release of the superoxide anion from mitochondria to cytosol. J Biol Chem 278(8): pp5557-5563.

Han I, Yun M, Kim EO, Kim B, Jung MH, Kim SH (2014) Umbilical cord tissue-derived mesenchymal stem cells induce apoptosis in PC-3 prostate cancer cells through activation of JNK and downregulation of PI3K/AKT signaling. Stem Cell Res Ther 5(2): pp54.

Haubner F, Muschter D, Pohl F, Schreml S, Prantl L, Gassner HG (2015) A co-culture model of fibroblasts and adipose tissue-derived stem cells reveals new insights into impaired wound healing after radiotherapy. Int $J$ Mol Sci 16(11): pp25947-25958.
Hendijani F, Javanmard SH (2015) Dual protective and cytotoxic benefits of mesenchymal stem cell therapy in combination with chemotherapy/ radiotherapy for cancer patients. Crit Rev Eukaryot Gene Expr 25(3): 203-207.

Houthuijzen JM, Daenen LGM, Roodhart JML, Voest EE (2012) The role of mesenchymal stem cells in anti-cancer drug resistance and tumour progression. Br J Cancer 106(12): pp1901.

Jeong KY, Lee EJ, Kim SJ, Yang SH, Sung YC, Seong J (2015) Irradiationinduced localization of IL-12-expressing mesenchymal stem cells to enhance the curative effect in murine metastatic hepatoma. Int $J$ Cancer 137(3): pp721-730.

Khakoo AY, Pati S, Anderson SA, Reid W, Elshal MF, Rovira II, Nguyen AT, Malide D, Combs CA, Hall G, Zhang J (2006) Human mesenchymal stem cells exert potent antitumorigenic effects in a model of Kaposi's sarcoma. J Exp Med 203(5): pp1235-1247.

Li Y, Xu J, Mao L, Liu Y, Gao R, Zheng Z, Chen W, Le A, Shi S, Wang S (2013) Allogeneic mesenchymal stem cell therapy for bisphosphonate-related jaw osteonecrosis in Swine. Stem Cells Dev 22(14): pp2047-2056.

Liang X, So YH, Cui J, ZHAO XU X, Y CAI L, LI W (2011) The low-dose ionizing radiation stimulates cell proliferation via activation of the MAPK/ ERK pathway in rat cultured mesenchymal stem cells. J Radiat Res 52(3): pp380-386.

Liotta F, Querci V, Mannelli G, Santarlasci V, Maggi L, Capone M, Rossi MC, Mazzoni A, Cosmi L, Romagnani S, Maggi E (2015) Mesenchymal stem cells are enriched in head neck squamous cell carcinoma, correlates with tumour size and inhibit T-cell proliferation. Br J Cancer 112(4): pp745.

Liu Q, Guan JZ, Sun Y, Le Z, Zhang P, Yu D, Liu Y (2017) Insulin-like growth factor 1 receptor-mediated cell survival in hypoxia depends on the promotion of autophagy via suppression of the PI3K/Akt/mTOR signaling pathway. Mol Med Rep 15(4): pp2136-2142.

Lu AG, Feng H, Pu-Xiong-Zhi Wang DP, Han XHC, Zheng MH (2012) Emerging roles of the ribonucleotide reductase M2 in colorectal cancer and ultraviolet-induced DNA damage repair. World J Gastroenterol 18(34): pp4704.

Ma Y, Hao X, Zhang S, Zhang J (2012) The in vitro and in vivo effects of human umbilical cord mesenchymal stem cells on the growth of breast cancer cells. Breast Cancer Res Treat 133(2): pp473-485.

Mayer-Wagner S, Passberger A, Sievers B, Aigner J, Summer B, Schiergens TS, Jansson V, Müller PE (2011) Effects of low frequency electromagnetic fields on the chondrogenic differentiation of human mesenchymal stem cells. Bioelectromagnetics 32(4): pp283-290.

Mishra PJ, Mishra PJ, Humeniuk R, Medina DJ, Alexe G, Mesirov JP, Ganesan S, Glod JW, Banerjee D (2008) Carcinoma-associated fibroblast-like differentiation of human mesenchymal stem cells. Cancer Res 68(11): pp4331-4339.

Nakamura K, Ito Y, Kawano Y, Kurozumi K, Kobune M, Tsuda H, Bizen A Honmou O, Niitsu Y, Hamada H (2004) Antitumor effect of genetically engineered mesenchymal stem cells in a rat glioma model. Gene Ther 11(14): pp1155.

Nicolay NH, Perez RL, Saffrich R, Huber PE (2015) Radio-resistant mesenchymal stem cells: mechanisms of resistance and potential implications for the clinic. Oncotarget 6(23): pp19366.

Özcan S, Alessio N, Acar MB, Toprak G, Gönen ZB, Peluso G, Galderisi U (2015) Myeloma cells can corrupt senescent mesenchymal stromal cells and impair their anti-tumor activity. Oncotarget 6(37): pp39482.

Özcan S, Alessio N, Acar MB, Mert E, Omerli F, Peluso G, Galderisi U (2016) Unbiased analysis of senescence associated secretory phenotype (SASP) to identify common components following different genotoxic stresses. Aging 8(7): pp1316.

Pommey S, Galipeau J (2006) The use of mesenchymal stromal cells in oncology and cell therapy. Bull Cancer 93(9): pp901-907.

Quante M, Tu SP, Tomita H, Gonda T, Wang SS, Takashi S, Baik GH, Shibata W, DiPrete B, Betz KS, Friedman R (2011) Bone marrow-derived myofibroblasts contribute to the mesenchymal stem cell niche and promote tumor growth. Cancer Cell 19(2): pp257-272.

Rieger KE, Chu G (2004) Portrait of transcriptional responses to ultraviolet and ionizing radiation in human cells. Nucleic Acids Res 32(16): pp4786-4803.

Sandra F, Matsuki NA, Takeuchi H, Ikebe T, Kanematsu T, Ohishi M, Hirata M (2002) TNF inhibited the apoptosis by activation of Akt serine/ threonine kinase in the human head and neck squamous cell carcinoma. Cell Signal 14(9): pp771-778. 
Sato K, Imai T, Okayasu R, Shimokawa T (2014) Heterochromatin domain number correlates with $\mathrm{X}$-ray and carbon-ion radiation resistance in cancer cells. Radiat Res 182(4): pp408-419.

Schaue D, Kachikwu EL, McBride WH (2012) Cytokines in radiobiological responses: a review. Radiat Res 178(6): pp505-523.

Schreuders EH, Ruco A, Rabeneck L, Schoen RE, Sung JJ, Young GP, Kuipers EJ (2015) Colorectal cancer screening: a global overview of existing programmes. Gut 64(10): pp1637-1649.

Sologuren I, Rodríguez-Gallego C, Lara PC (2014) Immune effects of high dose radiation treatment: implications of ionizing radiation on the development of bystander and abscopal effects. Transl Cancer Res 3(1): pp18-31.

Wang D, Park JS, Chu JS, Krakowski A, Luo K, Chen DJ, Li S (2004) Proteomic profiling of bone marrow mesenchymal stem cells upon transforming growth factor $\beta 1$ stimulation. J Biol Chem 279(42): pp43725-43734.

Wilson JG, Liu KD, Zhuo H, Caballero L, McMillan M, Fang X, Cosgrove K, Vojnik R, Calfee CS, Lee JW, Rogers AJ (2015) Mesenchymal stem (stromal) cells for treatment of ARDS: a phase 1 clinical trial. Lancet Respir Med 3(1): pp24-32.

Wirsdörfer F, Jendrossek V (2016) The role of lymphocytes in radiotherapyinduced adverse late effects in the lung. Front Immunol 7: 591.
Xiang J, Tang J, Song C, Yang Z, Hirst DG, Zheng QJ, Li G (2009) Mesenchymal stem cells as a gene therapy carrier for treatment of fibrosarcoma. Cytotherapy 11(5): pp516-526.

Xue J, Zhu Y, Sun Z, Ji R, Zhang X, Xu W, Yuan X, Zhang B, Yan Y, Yin L, Xu H (2015) Tumourigenic hybrids between mesenchymal stem cells and gastric cancer cells enhanced cancer proliferation, migration and stemness. BMC Cancer 15(1): pp793.

Yang HY, Qu RM, Lin XS, Liu TX, Sun QQ, Yang C, Li XH, Lu W, Hu XF, Dai JX, Yuan L (2014) IGF-1 from adipose-derived mesenchymal stem cells promotes radioresistance of breast cancer cells. Asian Pac J Cancer Prev 15(23): pp10115-10119.

Zhukareva V, Obrocka M, Houle JD, Fischer I, Neuhuber B (2010) Secretion profile of human bone marrow stromal cells: donor variability and response to inflammatory stimuli. Cytokine 50(3): pp317-321.

Zinöcker S, Vaage JT (2012) Rat mesenchymal stromal cells inhibit T cell proliferation but not cytokine production through inducible nitric oxide synthase. Front Immunol 3.

This work is published under the standard license to publish agreement. After 12 months the work will become freely available and the license terms will switch to a Creative Commons AttributionNonCommercial-Share Alike 4.0 Unported License.

Supplementary Information accompanies this paper on British Journal of Cancer website (http://www.nature.com/bjc) 